Research

\title{
Pathway of sodium alginate synthesis from marine brown algae, Sargassum wightii from Sri Lanka
}

\author{
G. D. T. M. Jayasinghe ${ }^{1}$ B. K. K. K. Jinadasa' ${ }^{1}$ N. A. G. Sadaruwan ${ }^{2}$ \\ Received: 22 October 2021 / Accepted: 30 November 2021 \\ Published online: 04 January 2022 \\ (c) The Author(s) 2021 OPEN
}

\begin{abstract}
Alginates are natural polysaccharides that are extracted from brown seaweed varieties and it is widely used for their rheological properties. The main step in the extraction protocol of sodium alginate is alkaline extraction. Sodium alginate was produced by dipping the seaweed in $1 \%$ formaldehyde and $2.5 \%$ of sodium carbonate solution and properties were studied following the standard methods. The amount of sodium alginate yield was $31.7 \%$ in Sargassum wightii. The moisture content and the ash content were recorded at $16.82 \%$ and $5.20 \%$, respectively. The viscosity and the gel strength were noted as $40 \mathrm{vcP}, 4.54 \times 10^{-2} \mathrm{kN}$ with $0.1 \mathrm{M} \mathrm{CaCl}_{2}$ and $6.86 \times 10^{-2} \mathrm{kN}$ with $0.2 \mathrm{M} \mathrm{CaCl}_{2}$ respectively. This study of the extraction method and its properties reveal that Sargassum wightii brown seaweed species have a high affinity to extract the alginate.
\end{abstract}

Keywords Sargassum wightii $\cdot$ Alginate $\cdot$ Alkaline extraction $\cdot$ Viscosity

\section{Introduction}

Brown algae (Phaeophyta) cell wall has a fibrillar section formed of cellulose micro fibrils, which is embedded with acid polysaccharides, linked to each other by protein [1]. The acid polysaccharides are mainly composed of fucoidans (sulphated fucans) and alginic acid, which are helping to structural toughness, and flexibility to the algae [2]. The word "alginate" is a generic term meaning of the various derivatives of the alginic acid either occurred naturally or produced from the natural derivatives [3]. Alginate mainly consists of $a-\mathrm{L}$ guluronic acid (G) and $\beta$-D mannuronic acid (M) units [4-6]. Due to the rheological properties of these polysaccharides, it is widely used in various fields of industries [7].

Countries in Asia have a long history of seaweed farming for food and other industrial purposes [8]. Now it is widely spreading to the rest of the world. Due to this reason, most Asian counties are cultivating and collecting a wide variety of seaweed [9]. Alginate is extracted from brown seaweed and it has been widely used in many fields such as immobilization technology, tissue engineering, pharmaceutical industry, and food applications as a stabilizer, gelling agent, thickening agent, edible coating for some foods, and textile industry [10]. The alginate content of brown seaweed varies depending upon the environmental conditions such as salinity, temperature, wave-current, species, the season of harvesting, and method of extraction used, etc. [11, 12].

Sodium Alginate (SA) obtained from brown algae, signifies a biodegradable, non-toxic polymer and most versatile polysaccharide in nature. Sodium Alginate is a well-known polysaccharide in the food packaging industry and is used

$\checkmark$ G. D. T. M. Jayasinghe, thilinimjayasinghe@gmail.com | 'Analytical Chemistry Laboratory, National Aquatic Resources Research and Development Agency (NARA), Colombo, Sri Lanka. ${ }^{2}$ Department of Food Science and Technology, Faculty of Agriculture, University of Peradeniya, Peradeniya, Sri Lanka. 
as edible films. However, the fragility and the high sensitivity to water remain of SA leads to difficulties of widespread food packaging applications. Therefore, SA mixed with other polysaccharides or protein to make the edible films and it becomes the most simple and attractive strategy for improving the properties [13]. Luis and his team investigated the effect of adding a low concentration of nano- $\mathrm{SiO}_{2}$ in the properties of the films based on $\mathrm{SA}$ and it has been reported with great success in improving mechanical and thermal properties. The film moisture content and water vapour barrier decreased due to the increase of nano $\mathrm{SiO}_{2}$ level [14]. According to the literature, SA extracted from this species has given promising yield and viscosity of the products [15].

Alginate is extracted from brown seaweed; by analytical method mainly focuses on the conversion of insoluble alginate present in the cell wall as magnesium and calcium alginate to a soluble form usually in sodium alginate [16]. The common extraction method of alginate has five steps: acidification, alkaline extraction, solid/liquid separation, precipitation, and drying [17]. During the acidification process, the seaweed becomes acidified and it is facilitated to alkaline extraction. Acidify seaweed are immersed in the sodium carbonate solution to convert the insoluble alginic acid into soluble sodium alginate [18]. The quantity of the yield is highly dependent on the volume of reactant, extraction time, and the brown seaweed species. The alkaline extraction time is influencing the rheological properties of the alginate and the reaction condition seems to favor bacterial growth and development. Vauchel et al. noted alginate degradation could occur due to bacterial development [1].

Among approximately 320 species of seaweed around the Sri Lankan coast, nearly 50-60 species have potential commercial importance. Brown seaweed such as Sargassum, has a great economic potential for the vast array of industries that have not yet been commercially utilized [19]. In the present study, we report on the extraction of alginates from brown algae species (Sargassum wightii) collected from the Southern coast of Sri Lanka. Through this study, we determine the optimum condition of the extraction method and evaluate their quality with commercially available alginate samples.

\section{Material and methodology}

\subsection{Seaweed collection and drying}

Sargassum wightii samples were collected from shallow seawater in the Southern coastal area, Sri Lanka. The samples were thoroughly washed with seawater, then cleaned with tap water to remove sands and other impurities. Finally, samples were washed with distilled water and dried under sunlight on a mesh, scattered in a layer that had a height of 4-5 cm for $12 \mathrm{~h}$. The temperature and the time duration were recorded to determine the time, which was needed to remove the moisture content of seaweed until $20 \%$.

\subsection{Production of sodium alginate}

McHugh et al. [17, 18] method was followed with slight modification to alginate extraction. Dried seaweed was dipped in $1 \% \mathrm{CaCl}_{2}$ solution (AR, Sigma Aldrich, Germany) for $2 \mathrm{~h}$ and then again dipped in $1 \%$ formaldehyde solution (AR, Merck, Germany) for $6 \mathrm{~h}$. Then the sample was washed with deionized water three times. Thereafter, samples were dipped in 5\% $\mathrm{HCl}$ solution (AR, Sigma Aldrich, Germany) for $30 \mathrm{~min}$ and again washed with deionized water three times. Then prepared the $2.5 \% \mathrm{Na}_{2} \mathrm{CO}_{3}$ solution (AR, Sigma Aldrich, German) and washed seaweed sample was dipped in this solution for $3 \mathrm{~h}$. After $3 \mathrm{~h}$, seaweed was removed from the solution by filtration and the filtrate was separated. Then ethanol $(95 \%, A R$, Sigma Aldrich, Germany) was added to the filtrate in a 2:3 ratio to precipitate fibrous alginic acid from the mixture. The mixture was stirred to complete the precipitation and precipitate was squeezed manually to remove the liquid phase. Finally, precipitation was dried in an oven (Memmert, UFE-500, United Kingdom) at $50^{\circ} \mathrm{C}$ for $12 \mathrm{~h}$ and milled.

\subsection{Yield}

The yield is expressed as the weight percentage of alginate with the weight of the seaweed samples. Approximately $100 \mathrm{~g}$ of dried seaweed were taken for alginate extraction and the final yield was calculated as the weight percentage for $100 \mathrm{~g}$ of dried seaweed. The formaldehyde concentration (FA) and the $\mathrm{Na}_{2} \mathrm{CO}_{3}$ concentration were optimized to take the best yield. 


\subsection{Properties of sodium alginate}

\subsubsection{Water content and ash content}

The water content was obtained by the gravimetric method by drying the sample of alginate at the temperature of $105^{\circ} \mathrm{C}$, overnight in the oven (Memmert, UFE-500, UK). The ash content was obtained by the both method are know as gravimetric by burning the alginate sample in muffle furnace (Carbolite GLM, United Kingdom) at the temperature of $250^{\circ} \mathrm{C}$ for $12 \mathrm{~h}$ until it becomes ash. All the samples were replicated thrice $(n=3)$.

\subsubsection{Insoluble matter test}

Alginate sample $(1 \mathrm{~g})$ was dissolved in $5 \mathrm{~mL}$ of $1 \mathrm{M} \mathrm{NaOH}$ and magnetic stirring (Labtech, South Korea) for $30 \mathrm{~min}(\mathrm{n}=3)$. The mixture was filtered through a suction filter unit and filter paper was dried at $100{ }^{\circ} \mathrm{C}$ until the weight become constant.

\subsubsection{Viscosity test}

Viscosity was tested by Brookfield viscometer (Model BL, Tokimec Inc, Japan) with a number 2 needle at 60 rpm. Calculation of viscosity was done with the reading and the cofactor, which is relevant to needle number 2, and 60-rpm rotation speed with the following equation $(n=3)$.

$$
\text { Viscosity }=\text { Dial reading } \times \text { Cofactor }
$$

\subsubsection{Testing for gel strength}

Extracted 2\% (W/V) of the alginic acid solution was mixed with $0.1 \mathrm{M}$ and $0.2 \mathrm{M} \mathrm{CaCl}_{2}$ solution while stirring to make the gel sample. Gel strengths were tested by using Instron Universal Tensile Tester (Model 4465, Instron Corporation, United Kingdom) with a $2 \mathrm{kN}$ load and $150 \mathrm{~mm} / \mathrm{min}$ position speed.

\subsubsection{International commission on illumination (CIE) L.a.b values for colour determination}

It is expressed colour of three values; $L$ for perceptual lightness, $a$ and $b$ for the four unique colour of human vision known as red, green, blue and yellow. Formaldehyde percentage was optimized with two concentration levels $(0.25 \%$, $1 \%)$ for taking the colour of the yield. Both two concentration levels were compared with the samples extracted without formaldehyde $(n=3)$.

\subsubsection{Metal analysis}

Samples were grind using a domestic food blender and sieved, then $0.5 \mathrm{~g}$ of each sample mineralized in Teflon digestion vessels in a closed microwave accelerated system (CEM, MARS 6, USA) using $10 \mathrm{~mL}$ nitric acid (AR, Sigma, USA) as a reagent. Atomic absorption spectrophotometer (AAS) (Varian 240 FS, Varian Inc., Australia) was used to determine the mercury $(\mathrm{Hg})$, cadmium $(\mathrm{Cd})$, lead $(\mathrm{Pb})$, arsenic $(\mathrm{As})$, in the prepared samples. Vapour generation accessory (Varian VGA-77) with the closed-end cell was used for Hg determination. A graphite tube atomizer (Varian GTA-120) was used for $\mathrm{Cd}, \mathrm{As}$, and $\mathrm{Pb}$. The calibration curves for all the metals were obtained with a series of standard solutions, which were prepared using the above mentioned standard solutions. All the samples were replicated thrice.

\subsubsection{Statistical analysis}

Statgraphics Centurion XVI v 16.1.15 (Manugistics Inc.Rockville, MD, USA) software was used for statistical evaluation (ANOVA) for comparing standard deviation and mean values, respectively. 
Table 1 Removal of moisture in seaweed with drying hours
Time duration of drying (hours)

4

8

12

16

$\mathrm{SD}$, standard deviation

\begin{tabular}{llllll}
\hline Treatment & $\Delta \mathrm{E}$ & $\Delta \mathrm{L}$ & $\Delta \mathrm{a}$ & $\Delta \mathrm{b}$ & Visual observation \\
\hline Without FA & 52.6 & $-49.9 \pm 2.42$ & $+16.0 \pm 1.25$ & $+4.0 \pm 2.11$ & Blackish colour \\
$0.25 \%$ & 36.1 & $-29.5 \pm 1.60$ & $+12.1 \pm 0.96$ & $+16.8 \pm 1.87$ & Brownish colour \\
$1 \%$ & 28.7 & $-20.9 \pm 3.11$ & $+6.3 \pm 1.18$ & $+18.7 \pm 0.97$ & Brownish yellow colour \\
\hline
\end{tabular}

$\Delta$, positive or negative; L, lightness; a, red/green coordination; b, green/blue coordination; $E$, total difference

\begin{tabular}{ll} 
& moisture \\
\hline 4 & $86.28 \pm 0.71$ \\
8 & $42.80 \pm 4.79$ \\
12 & $16.81 \pm 3.25$ \\
\hline
\end{tabular}

Average (\%)+SD

of the remaining

moisture

$86.28 \pm 0.71$

$16.81 \pm 3.25$
Table 2 L.a.b value for different FA concentration levels

\section{Results and discussion}

Drying of seaweed aims to reduce the water content of the mass, making it easy to handle and increasing the absorption of the chemicals during the extraction process. During the drying, process seaweed should not be subjected to the higher temperature for long periods due to degrading the alginate [20]. To minimize the yield loss, dried the seaweed for $8 \mathrm{~h}$ at $50^{\circ} \mathrm{C}$ or sun drying for $12 \mathrm{~h}$ can be used. During the sun drying, the moisture content was reduced with time as follows (Table 1).

A Statistical evaluation was performed by comparing the standard deviation and average value of the moisture content of the seaweed with time. ANOVA was applied for comparison of the average moisture content and statistically significant difference $(p=0.000)$ between the means of the four variables at the $95 \%$ significant level. Multiple comparison procedure was applied to determine which means are significantly different from each other. All pairs showed a statistically significant difference at the $95 \%$ confidence level. Approximately $80 \%$ of the moisture content was removed after $12 \mathrm{~h}$ sun-drying process. The temperature under the sun drying has fluctuated from 30 to $50^{\circ} \mathrm{C}$. Previous researchers recorded the best moisture content in the seaweed for storage was less than 20\% [21]. Due to that reason, we selected $12 \mathrm{~h}$ of sun-drying best for the removal of the moisture from seaweed.

According to the literature, drying is affected to leaching some compounds such as mannitol, laminarin, and forms brown pigments like fucoidan in the seaweed cells. These pigments are highly affect the purity and the colour of the final product. To avoid this issue, formaldehyde and hydrochloric acid treatment were used to remove the pigments from the sample. The seaweed was dipped in the $1 \%$ of $\mathrm{CaCl}_{2}$ solution for $2 \mathrm{~h}$ and the alginate was precipitated as calcium alginates [22]. McHugh et al. noted the calcium alginate is a fibrous material that can be readily separated on a metal screen, treated with chlorine to bleach the product. After being treated with dilute mineral acid it can be obtained alginic acid in fibrous forms. Alginic acid can be converted into sodium alginate by neutralizing it with alkaline [23].

The formaldehyde concentration (FA) and $\mathrm{Na}_{2} \mathrm{CO}_{3}$ concentrations were optimized to take the maximum yield. Formaldehyde was added in two concentrations $(0.25 \%, 1 \%)$ and a blank test was run simultaneously. Some studies reported a lower concentration of FA $(0.1 \%)$ and during the test, all other parameters were constant except the FA concentration [23]. The colour of the final product was determined with the international commission on illumination (ICI) L.a.b values. Table 2 shows the L.a.b values for different FA concentrations. Figure 1 shows the observed colour difference in the samples for different FA concentrations levels.

According to the ANOVA table of ' $L$ ', the $p$-value is less than 0.05 ( $95 \%$ confidence interval) and there was a significant difference between the three variables. In the application of multiple comparisons for individual samples, there was no significant difference between 0.25 and 1\% FA samples. ANOVA table of the ' $a$ ', the $p$-value is less than 0.05 , and three 
Fig. 1 Colour different in different FA concentrations

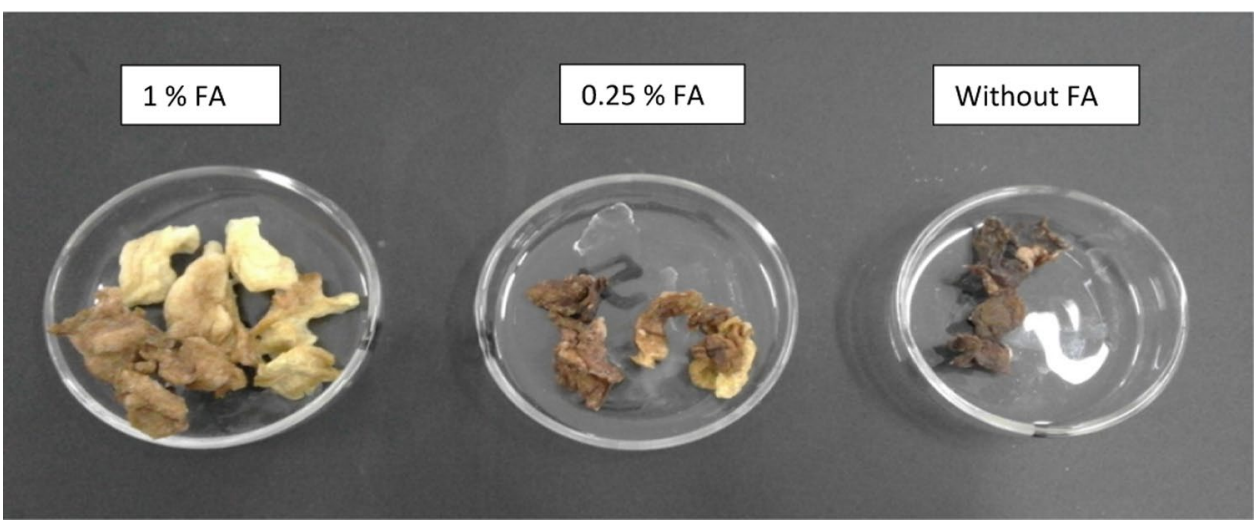

variables were significantly different. Base on the multiple comparisons there was no significant difference between $0.25 \%$ FA used to sample with and without FA used. ANOVA table for ' $b$ ', there was a significant difference between 3 variables but multiple comparisons for individual samples proved that there was no significant difference between FA used samples.

According to the L.a.b value, the best FA concentration is $1 \%$ due to the brownish-yellow in colour of the final product. The use of $5 \% \mathrm{HCl}$ solution during the pre-extraction hydrolyzed the seaweed cell wall, reduced the impurities and made alginate for more easy extraction [24].

The use of $\mathrm{Na}_{2} \mathrm{CO}_{3}$ during extraction allows the separation of cellulose from the alginate-contained cell wall by increasing the yield [25]. Hence, the different concentrations of $\mathrm{Na}_{2} \mathrm{CO}_{3}(1.5,2.0,2.5,3.0,5.0$ and 7.5\%) were used in extraction process in order to select the optimum concentration. Figure 2 shows the yield $\%$ of the different concentration levels. The highest yield was found in the $2.5 \% \mathrm{Na}_{2} \mathrm{CO}_{3}$ concentration level.

Parthiban et al. reported the maximum yield of sodium alginate found in the Sargassum species than other species and it was noted as $31.7 \%$ [3]. The highest moisture and ash content in the final product of our alginate was recorded as $16.82 \%$ and $5.2 \%$ respectively. Moisture content was approximately similar to the previously published value. Parthiban et al. noted the Padina sp. had higher ash content than Sargassum sp. Thallus of the Sargassum sp., which is not directly; connect to the bottom of the shore. But thallus of the Padina sp. directly contacts to the bottom of the shore. Due to that reason, there was low mineral content in their thallus of the Sargassum sp. The viscosity and the gel strength were also measured in the final product. The recorded viscosity and gel strength was $40 \mathrm{vcP}, 4.54 \times 10^{-2} \mathrm{kN}$ with $0.1 \mathrm{M} \mathrm{CaCl}_{2}$ and $6.86 \times 10^{-2} \mathrm{kN}$ with $0.2 \mathrm{M} \mathrm{CaCl}_{2}$ respectively. The insoluble matter percentage by mass in the alginate was observed as $0.4 \%$.

Under the trace metal content, we analysed the $\mathrm{Hg}, \mathrm{Cd}, \mathrm{As}$, and $\mathrm{Pb}$. Mercury was not detected in the final product (LOD-0.07 mg/kg) and the $\mathrm{Pb}$, As and Cd concentrations were $2.11 \mathrm{mg} / \mathrm{kg}, 0.50 \mathrm{mg} / \mathrm{kg}$, and $0.44 \mathrm{mg} / \mathrm{kg}$ respectively. The Southern coastal area in Sri Lanka is a very famous area for tourism and most of the industries are located in this area. The number of rivers mouth open to the Southern coastal area. It may be the reason for a considerable amount of some metal (eg., $\mathrm{Pb}$ ) accumulating in the seaweed.

According to the specification of the Indian standard for alginic acid in food-grade (IS 7928:1993), they recommended the requirements need to be fulfilled to use for food-grade [26]. Table 3 shows the comparison of the final product with the Indian standard.

Fig. 2 Yield \% at the different concentration levels of $\mathrm{Na}_{2} \mathrm{CO}_{3}$

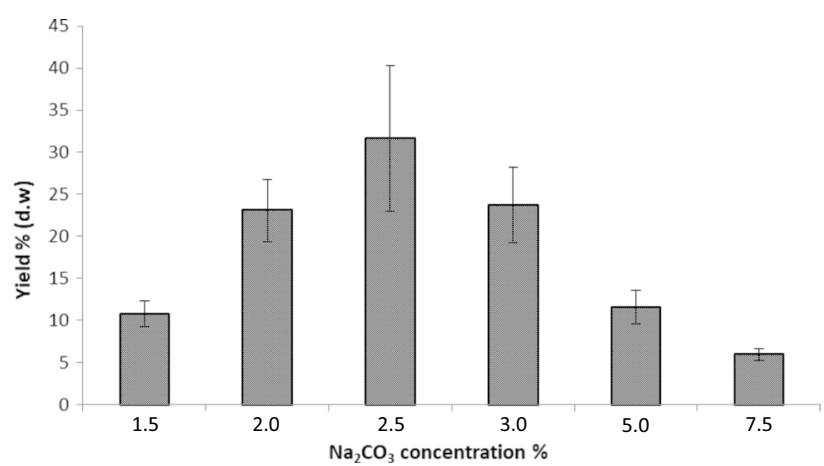


Table 3 Comparison of the final product with Indian standard

\begin{tabular}{lll}
\hline Parameter & Indian specification & Value of extract \\
\hline Purity, \%, (minimum) & 91 & Not calculated \\
Moisture, \%, (maximum) & 15 & 16.82 \\
Insoluble matter, \%, (maximum) & 0.2 & 0.4 \\
Ash, \%, (maximum) & 4 & 5.2 \\
Acid insoluble ash, \%, (maximum) & 0.5 & Not calculated \\
Lead, Pb, mg/kg, (maximum) & 10 & 2.11 \\
Arsenic, As, mg/kg, (maximum) & 3 & 0.50 \\
Cadmium, Cd, mg/kg (maximum) & Not mention & 0.44 \\
Mercury, Hg, mg/kg (maximum) & Not mention & $<0.07$ \\
E-coli, and Salmonella & Absent & Not calculated \\
\hline
\end{tabular}

The result shows that the final product of alginate slightly deviated from the Indian specification. From the results mentioned above, the use of Sargassum wightii species collected from the Southern coastal area must be considered due to the high affinity to extract the alginate. Further studies are needed to determine the availability of the resources, purity, and microbiological parameters of the final products.

\section{Conclusion}

The results of the present study indicated that the alginate obtained at the laboratory level from the algae Sargassum wightii can be produced at the pilot level with the technology development. To better synthesis of alginate, it is necessary to apply $1 \%$ formaldehyde with $2.5 \% \mathrm{Na}_{2} \mathrm{CO}_{3}$ for a higher yield. As a food additive, attention needs to be paid to the use of alginate with quality and safety. Algae are highly enriched with heavy metals, polychlorinated biphenyls (PCBs) and other environmental contaminants in seawater. In the terms of heavy metals, the present study reported lead, cadmium and arsenic. Therefore, to ensure the safety of seaweed utilization by strictly monitoring and controlling the environment of seaweed breeding and growth. In short, due to its properties such as viscosity, gel strength, insoluble matter, etc., alginic acid will expand its use. Developing new products using alginic acid will be a valuable and promising research direction.

Acknowledgements The authors would like to acknowledge to, laboratory staff in Analytical Chemistry Laboratory, National Aquatic Resources Research and Development Agency (NARA) for their support.

Authors' contributions GDTMJ and BKKKJ equally contributed to the manuscripts. The design idea, plan, and statistical analysis of the research and wrote the manuscript. NAGS conducted the laboratory analysis. All authors read and approved the final manuscript.

Data availability The datasets generated during and/or analysed during the current study are available from the corresponding author on reasonable request.

\section{Declarations}

Competing interests The authors declare no competing interests.

Open Access This article is licensed under a Creative Commons Attribution 4.0 International License, which permits use, sharing, adaptation, distribution and reproduction in any medium or format, as long as you give appropriate credit to the original author(s) and the source, provide a link to the Creative Commons licence, and indicate if changes were made. The images or other third party material in this article are included in the article's Creative Commons licence, unless indicated otherwise in a credit line to the material. If material is not included in the article's Creative Commons licence and your intended use is not permitted by statutory regulation or exceeds the permitted use, you will need to obtain permission directly from the copyright holder. To view a copy of this licence, visit http://creativecommons.org/licenses/by/4.0/.

\section{References}

1. Vauchel $P$, et al. A new process for extracting alginates from Laminaria digitata: reactive extrusion. Food Bioprocess Technol. 2008;1(3):297-300. 
2. García-Ríos V, et al. Polysaccharides composition from tropical brown seaweeds. Phycol Res. 2012;60(4):305-15.

3. Parthiban C, et al. Production of sodium alginate from selected seaweeds and their physiochemical and biochemical properties. Asian Pac J Trop Biomed. 2012;1:1-4.

4. McHugh DJ. Production, properties and uses of alginates. In: McHugh DJ, editor. Production and utilization of products from commercial seaweeds, vol. 288. Rome: FAO Fish Tech Pap; 1987. p. 58-115.

5. Leal D, et al. FT-IR spectra of alginic acid block fractions in three species of brown seaweeds. Carbohyd Res. 2008;343(2):308-16.

6. Ale MT, Mikkelsen JD, Meyer AS. Important determinants for fucoidan bioactivity: a critical review of structure-function relations and extraction methods for fucose-containing sulfated polysaccharides from brown seaweeds. Mar Drugs. 2011;9(10):2106-30.

7. Reyes-Tisnado R, et al. Food grade alginates extracted from the giant kelp Macrocystis pyrifera at pilot-plant scale. Rev Invest Mar. 2005;26(3):185-92.

8. Trono G Jr. Seaweed culture in the Asia-Pacific region. Rome: RAPA Publication (FAO); 1986.

9. Trono Jr G. Lessons from the history of seaweed culture in the Philippines and the trend of seaweed farming in Southeast Asia. In: regional workshop on seaweed culture and marketing, Suva (Fiji), 14-17 Nov 1989. 1990.

10. Zhao Y, Chen P. Natural products with health benefits from marine biological resources. Curr Org Chem. 2014;18(7):777-92.

11. Draget Kl, et al. lonic and acid gel formation of epimerised alginates; the effect of AlgE4. Int J Biol Macromol. 2000;27(2):117-22.

12. Mirshafiey A, Rehm BH. Alginate and its comonomer mannuronic acid: medical relevance as drugs. In: Alginates: biology and applications. Berlin: Springer; 2009. p. 229-60.

13. MarangoniJúnior $L$, et al. Water vapor sorption and permeability of sustainable alginate/collagen/SiO2 composite films. LWT. 2021;152: 112261.

14. MarangoniJúnior L, et al. Effect of low concentrations of SiO2 nanoparticles on the physical and chemical properties of sodium alginatebased films. Carbohydr Polym. 2021;269: 118286.

15. Jayasankar R. On the yield and quality of sodium alginate from Sargassum wightii (Greville) by pre-treatment with chemicals. Seaweed Res Utilin. 1993;16(1 \& 2):63-6.

16. Lin T-Y, Hassid W. Pathway of alginic acid synthesis in the marine brown alga, Fucus gardneri Silva. J Biol Chem. 1966;241(22):5284-97.

17. McHugh DJ. A guide to the seaweed industry. Rome: Food and Agriculture Organization of the United Nations; 2003.

18. McHugh D. A guide to the seaweed industry FAO fisheries technical paper 441. Rome: Food and Agriculture Organization of the United Nations; 2003.

19. Kariyawasam I. Seaweed mariculture: a potential "multi-million dollar industry. Sath Samudura; healthy oceans; healthy planet; $2016 . \mathrm{p}$. 44-49.

20. Fudholi A et al. The effects of drying air temperature and humidity on drying kinetics of seaweed. Recent research in geography, geology, energy, environment and biomedicine; 2011. p. 129-133.

21. Dring M. Photosynthesis of intertidal brown algae during and after periods of emersion: a renewed search for physiological causes of zonation. Mar Ecol Prog Ser. 1982;8(3):301-8.

22. Gupta S, Cox S, Abu-Ghannam N. Effect of different drying temperatures on the moisture and phytochemical constituents of edible Irish brown seaweed. LWT. 2011;44(5):1266-72.

23 McHugh DJ, et al. Pilot plant scale extraction of alginates from Macrocystis pyrifera 3. Precipitation, bleaching and conversion of calcium alginate to alginic acid. J Appl Phycol. 2001;13(6):471-9.

24. Mushollaeni W. The physicochemical characteristics of sodium alginate from Indonesian brown seaweeds. Afr J Food Sci. $2011 ; 5(6): 349-52$.

25. Truus K, Vaher M, Taure I. Algal biomass from Fucus vesiculosus (Phaeophyta): investigation of the mineral and alginate components. Proc Estonian Acad Sci Chem. 2001;50(2):95-103.

26. Coppen J, Nambiar P. Agar and alginate production from seaweed in India. Chennai: Bay of Bengal Programme; 1991.

Publisher's Note Springer Nature remains neutral with regard to jurisdictional claims in published maps and institutional affiliations. 